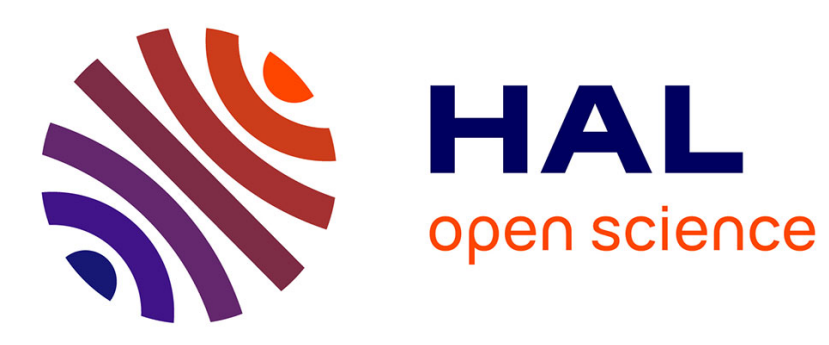

\title{
Long-term Home Ventilation of Children in Italy: a National Survey
}

Fabrizio Racca, Giacomo Berta, Marco Sequi, Elisabetta Bignamini, Elena

Capello, Renato Cutrera, Giancarlo Ottonello, Marco V Ranieri, Ida Salvo, Raffaele Testa, et al.

\section{To cite this version:}

Fabrizio Racca, Giacomo Berta, Marco Sequi, Elisabetta Bignamini, Elena Capello, et al.. Long-term Home Ventilation of Children in Italy: a National Survey. Pediatric Pulmonology, 2010, 46 (6), pp.566. 10.1002/ppul.21401 . hal-00613787

\section{HAL Id: hal-00613787 https://hal.science/hal-00613787}

Submitted on 6 Aug 2011

HAL is a multi-disciplinary open access archive for the deposit and dissemination of scientific research documents, whether they are published or not. The documents may come from teaching and research institutions in France or abroad, or from public or private research centers.
L'archive ouverte pluridisciplinaire HAL, est destinée au dépôt et à la diffusion de documents scientifiques de niveau recherche, publiés ou non, émanant des établissements d'enseignement et de recherche français ou étrangers, des laboratoires publics ou privés. 


\section{Long-term Home Ventilation of Children in Italy: a National Survey}

\begin{tabular}{|c|c|}
\hline Journal: & Pediatric Pulmonology \\
\hline Manuscript ID: & PPUL-10-0162.R2 \\
\hline Wiley - Manuscript type: & Original Article \\
\hline $\begin{array}{r}\text { Date Submitted by the } \\
\text { Author: }\end{array}$ & 10-Sep-2010 \\
\hline Complete List of Authors: & $\begin{array}{l}\text { Racca, Fabrizio; San Giovanni Battista-Molinette Hospital, University } \\
\text { of Turin, Department of Anesthesiology and Intensive Care Medicine } \\
\text { Berta, Giacomo; San Giovanni Battista-Molinette Hospital, } \\
\text { University of Turin, Department of Anesthesiology and Intensive } \\
\text { Care Medicine } \\
\text { Sequi, Marco; Mario Negri Research Institute, Public Health } \\
\text { Bignamini, Elisabetta; Regina Margherita University Children's } \\
\text { Hospital, Pulmonology Unit } \\
\text { Capello, Elena; San Giovanni Battista-Molinette Hospital, University } \\
\text { of Turin, Department of Anesthesiology and Intensive Care Medicine } \\
\text { Cutrera, Renato; Bambino Gesu' Children's Research Hospital, } \\
\text { Respiratory Unit } \\
\text { Ottonello, Giancarlo; G. Gaslini Institute, Anesthesiology and } \\
\text { Intensive Care Medicine Unit } \\
\text { Ranieri, Marco; San Giovanni Battista-Molinette Hospital, University } \\
\text { of Turin, Department of Anesthesiology and Intensive Care Medicine } \\
\text { Salvo, Ida; Vittore Buzzi Children's Hospital, Department of } \\
\text { Anesthesiology and Intensive Care } \\
\text { Testa, Raffaele; Santobono Hospital, Intensive Care Unit } \\
\text { Wolfler, Andrea; Vittore Buzzi Children's Hospital, Department of } \\
\text { Anesthesiology and Intensive Care } \\
\text { Bonati, Maurizio; Mario Negri Research Institute, Public Health }\end{array}$ \\
\hline Keywords: & $\begin{array}{l}\text { Chronic respiratory failure, home respiratory care, epidemiology, } \\
\text { disability, long term ventilation, home mechanical ventilation }\end{array}$ \\
\hline
\end{tabular}

\section{SCHOLARONE Manuscripts}




\section{Long-term Home Ventilation of Children in Italy: a National Survey}

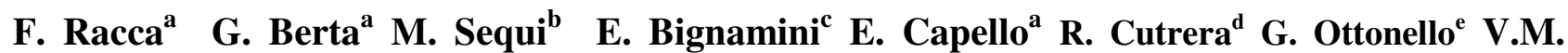
Ranieri" I. Salvo ${ }^{\mathrm{f}}$ R. Testa ${ }^{\mathrm{g}}$ A. Wolfler ${ }^{\mathrm{f}}$ and M. Bonati" on behalf of the "LTV Pediatric Italian Network"h

${ }^{a}$ Department of Anesthesiology and Intensive Care Medicine, San Giovanni Battista-Molinette Hospital, University of Turin, Turin, Italy.

${ }^{\mathrm{b}}$ Laboratory for Mother and Child Health, Department of Public Health, "Mario Negri" Pharmacological Research Institute, Milan, Italy

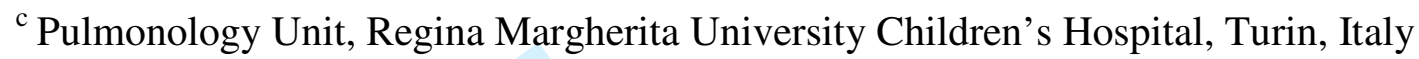

${ }^{\mathrm{d}}$ Respiratory Unit, Bambino Gesu' Children's Research Hospital, Rome, Italy

${ }^{\mathrm{e}}$ Anesthesiology and Intensive Care Medicine Unit, G. Gaslini Institute, Genoa, Italy

${ }^{\mathrm{f}}$ Department of Anesthesiology and Intensive Care, Vittore Buzzi Children’s Hospital, Milan, Italy

${ }^{\mathrm{g}}$ Intensive Care Unit, Santobono Hospital, Naples, Italy

hLTV Pediatric Italian Network": Anna Costantino, Alessandria; Raffaella Pagni, Ancona; Anna Maria Miorelli, Arco; Paolo Castaldi, Cagliari; Mariano Cabras, Carbonia; Bruno Dengo, Castelfranco Veneto; Augusto Biasini, Cesena; Francesco Morandi, Erba; Carlo Minetti, Giancarlo Ottonello, Genova; Paolo Banfi, Maurizio Bonati, Edoardo Calderini, Edi Prandi, Ida Salvo, Marco Sequi, Andrea Wolfler, Marco Zucconi, Milano; Giuseppe Fiorentino, Antonio Maddalena, Raffaele Testa, Napoli; Grazia Crescimanno, Anna Guddo, Palermo; Livio Carnevale, Pavia; Andrea Vianello, Padova; Giancarlo Piccinini, Ravenna; Valter Bottari, Reggio Emilia; Maurizio Corbari, Renato Cutrera, Martino Pavone, Roma; Giacomo Berta, Elisabetta Bignamini, Elena Capello, Lorenzo Del Sorbo, Cesare Gregoretti, Maria Maspoli, Fabrizio Racca, Marco V. Ranieri, Torino; Antonio Peratoner, Udine; Monica Benedetti, Verona.

Address correspondence to:

Maurizio Bonati, MD

Head of Department of Public Health and of the

Laboratory for Mother and Child Health

"Mario Negri" Pharmacological Research Institute

Via Giuseppe La Masa 19, 20156

Milan, Italy

Tel 00390239014.511

Fax 0039023550924

Email: mother_child@marionegri.it

Funding: none

Short title: Home Mechanical Ventilation for Italian Children 
Keywords: Chronic respiratory failure, home respiratory care, long term ventilation, home mechanical ventilation, epidemiology, artificial ventilation, disability.

Word count: 3019

Number of figures: 0
Number of tables: 1

Conflicts of interest: none. 


\begin{abstract}
Background: Improved technology, as well as professional and parental awareness, enable many ventilator-dependent children to live at home. However, the profile of this growing population, the quality and adequacy of home care, and patients' needs still require thorough assessment.
\end{abstract}

Objectives: To define the characteristics of Italian children receiving long-term home mechanical ventilation (HMV) in Italy.

Methods: A detailed questionnaire was sent to 302 National Health Service hospitals potentially involved in the care of HVM in children (aged $<17 \mathrm{yrs}$ ). Information was collected on patient characteristics, type of ventilation, and home respiratory care.

Results: A total of 362 HMV children was identified. The prevalence was 4.2 per 100,000 (95\% CI: 3.8-4.6), median age was 8 years (interquartile range 4-14), median age at starting mechanical ventilation was 4 years (1-11), and 56\% were male. The most frequent diagnostic categories were neuromuscular disorders (49\%), lung and upper respiratory tract diseases (18\%), hypoxic (ischemic) encephalopathy (13\%), and abnormal ventilation control (12\%). Medical professionals with nurses (for $62 \%$ of children) and physiotherapists (20\%) participated in the patients' discharge from hospital, though parents were the primary care give, $\mathrm{r}$ and in $47 \%$ of cases, the sole care giver. Invasive ventilation was used in $41 \%$ and was significantly related to young age, southern regional residence, longer time spent under mechanical ventilation, neuromuscular disorders, or hypoxic (ischemic) encephalopathy.

Conclusions: Care and technical assistance of long-term HMV children need assessment, planning, and resources. A wide variability in pattern of HMV was found throughout Italy. An Italian national ventilation program, as well as a national registry, could be useful in improving the care of these often critically ill children. 


\section{INTRODUCTION}

Continuous advances in neonatal and pediatric intensive care are likely to result in more infants, children, and adolescents with critical, chronic conditions, who survive and who are discharged home, but require long-term technological support. ${ }^{1-3}$ A growing population of children exists who has chronic respiratory failure due to conditions such as neuromuscular diseases, obstructive sleep apnea, craniofacial abnormalities, or spinal cord injuries, and who require either tracheostomy or mask ventilation.

Pressure to reduce the hospital stay of these children and awareness of the effects of long termhospitalization on a child's development have, during the last decade - especially, in a few countries such as UK, France, and US, - increased the numbers of ventilated children discharged home. However, the availability and practical details of complex respiratory support at home involve a lot of variables such as appropriate home environment, healthcare support, and funding, that cannot always be guaranteed. Findings of the Eurovent study, a wide cross sectional survey including adults as well as children, highlighted how the collection of information about home mechanical ventilation (HMV) could facilitate national planning for HMV. In particular, it could aid the development of HMV services in order to ensure equality of provision and access. ${ }^{3}$ Surveys in Canada, ${ }^{4,5}$ Chile,${ }^{6}$ Germany, ${ }^{7}$ France, ${ }^{8,9}$ Italy, ${ }^{10,11}$ Japan, ${ }^{12}$ New Zealand, ${ }^{13}$ Switzerland, ${ }^{14}$ The Netherlands, ${ }^{15}$ Turkey, ${ }^{16} \mathrm{UK},{ }^{17-19}$ and $\mathrm{USA}^{20-}{ }_{-} 22$ have defined the size, main features, and needs of the pediatric population requiring home mechanical ventilation. However there are many differences between these observational studies: the setting (single referring center, state, or country), the time period (one year or trend over time), the data collected, and how it was collected. Thus, estimates of the national prevalence of home ventilator-dependent children range from 0.7/100,000 children in 1993 in Japan ${ }^{12}$ to 3.4/100,000 in 2000 in Switzerland. ${ }^{14}$ Because information on long-term home ventilation for children in Italy is scant and erratic (no regional or national population-based data exist), this survey was conducted to describe the size and 
characteristics of the pediatric Italian population receiving chronic mechanical ventilation at home and the profile of home respiratory care.

\section{METHODS}

\section{Study Population}

A questionnaire was sent to all 27 Italian pediatric intensive care and pulmonary units to get data on children up to 17 years old receiving HMV in January 2007. To identify as many children as possible the questionnaire was sent also to another 275 hospital-based units (eg. pulmonary services, and critical care units) of the National Health Service (NHS) that are potentially involved in the care of the target population. Information referred to children discharged home from hospital whorequired tracheostomy or mask ventilation.

\section{Home respiratory care}

HMV was defined as invasive mechanical ventilation (IMV) or non invasive mechanical ventilation (NIV), for a period of at least 3 months on a daily basis, carried out mostly in the user's home or other long-term care facility (not a hospital). ${ }^{3}$ Basic demographic data (age, sex, place of residence), causes of respiratory failure, hospitalization history, duration of ventilatory support, type of ventilation and management-related description and home care provider information were collected.

\section{Data analysis}

Data were entered into a SAS/STAT database (Statistical Analysis Software, Cary, NC) for recording and analysis. The prevalence with 95\% confidence intervals (CI) of Italian children ventilated at home on the long term was calculated using the Istat 2007 annual report (Italian National Institute of Statistics) for children up to 17 years old, resident in the provinces in which patients were identified as the denominator. Age was calculated on the basis of the date of birth and the date of onset of ventilation was recorded. 
Descriptive statistics were computed for the entire study population and subgroups. Student's $t$ test was used to compare the type of ventilation and patient's age (continuous variable). $\chi^{2}$ tests were used to compare the type of ventilation and categorical variables, such as sex and home health care. The Mann-Whitney U test was used to compare the type of ventilation in each class of time/day spent under mechanical ventilation. ANOVA was used to check the association between the type of ventilation and class of diagnosis. Comparisons of the type of ventilation in each region were tested by $\chi_{\text {trend }}^{2}$ analysis. Multivariate logistic regression was used to look at the association between the type of ventilation and all monitored factors, simultaneously.

Results are presented as frequencies, or median and interquartile range; $\mathrm{P}<0.05$ was considered significant.

All data collected on centres and patients were kept strictly confidential. Data on patients were anonymous. The San Giovanni Battista-Molinette Hospital, University of Turin, Committee on Clinical Investigation reviewed and approved the study protocol. Because this was an observational study without an intervention and without the presentation of any identifying data, the committee ruled that informed consent was not necessary.

\section{RESULTS}

A total of 362 children were identified by 30 centers (67\% in the North of Italy) as receiving home mechanical ventilation in January 2007, with an estimated prevalence of 4.2 per 100,000 $\leq 17$ year old children (95\% CI 3.8-4.6). Patients were resident in 75 of the 107 Italian provinces (70\%); 200 (55\%) were resident in the North, 55 (15\%) in the Center, and 107 (30\%) in the South, in good agreement with the national distribution of children up to 17 years old. No difference was observed between the type of ventilation and the area of residence (Table 1). The majority of patients (59\%) were discharged from 12 of 27 NHS pediatric intensive care units or pediatric pulmonary units that were following mechanically ventilated children at home, and the others came from 18 other 
hospital units and wards (i.e., adult intensive care units, adult pulmonary units, pediatric neurology units, pediatric palliative care units). The median number of children followed by each center was seven (interquartile range 3-19).

The median age was 8 years (interquartile range 4-14) and was significantly different for children receiving invasive or non-invasive ventilation $(\mathrm{P}<<0.001)$, as well as for the median age at the start of mechanical ventilation $(\mathrm{P}<<0.001)$ (Table 1). All children received positive pressure ventilation. The majority of children receives NIV (Table 1), which is delivered mostly by nasal mask ( $85 \%$ of patients receiving NIV). Non-invasive ventilator support was the most used and skewed toward late infancy and adolescence.. Overall, $41 \%$ of the survey population had ventilation via tracheotomy with the highest percentage of children affected by neurological disorders. The median duration of home mechanical ventilation was one year (Table 1).

The most frequent diagnostic category was neuromuscular disorders (49\%), followed by lung and upper respiratory diseases (18\%), hypoxic (ischemic) encephalopathy (13\%), and abnormal ventilation control $(12 \%)$ (Table 1$)$. The most represented neuromuscular disorders were spinal muscular atrophy (SMA) (78 patients), Duchenne muscular dystrophy (31 patients) and Congenital muscular dystrophy (29 patients). In particular, 25 children were affected by SMA type 1 (16 receiving NIV, 64\%) and 53 children by SMA type 2 (30 receiving NIV, 57\%).

There were wide difference between the type of ventilation and diagnoses $(\mathrm{F}=5.94, \mathrm{P}<0.016$ ). Time per day spent under mechanical ventilation was longer for children requiring invasive ventilation $\left(\chi^{2}=148 ; \mathrm{P}<<0.001\right)$ (Table 1$)$, particularly for those with neuromuscular disorders $\chi^{2}$ $=73 ; \mathrm{P}<<0.001$ ), hypoxic (ischemic) encephalopathy $\left(\chi^{2}=37\right.$; $\mathrm{P}<<0.001$ ), or chronic lung and upper respiratory diseases $\left(\chi^{2}=28 ; \mathrm{P}<<0.001\right)$. Nurses (for $62 \%$ of children), physiotherapists (20\%), social workers (7\%), psychologists (7\%), pediatricians $(5 \%)$, and other professionals $(4 \%)$ participated in the home discharge process with hospital physicians. All children were involved in a patient ventilator training program (94\% during 
inpatient visits; $6 \%$ during outpatient visits) and in a regular monitoring program. At home visits were planned in $60 \%$ of patients (36\% of patients only during planned hospitalization, $30 \%$ only during outpatient visits, $29 \%$ with both modalities, 5 and $\%$ only at home). The mean number of hospital visits was 2.8/year, while the mean number of at home visits was $27 /$ year. The at home visit program involves general practitioners (63\% of patients), hospital physicians (65\% of patients), nurses (49\% of patients), physical therapists (22\% of patients). Arterial blood gases (59\% of patients), sleep study (41\% of patients), and nocturnal pulse oximetry (33\% of patients), were the principal investigations during monitoring program.

The majority of children with a tracheotomy had uncuffed tube $(64,2 \%)$. The at home tracheotomy tube changes were performed by parents (39\% of tracheotomised patients), by intensivists (25\%), by nurses $(19 \%)$, by pulmonologists $(10 \%)$, or by others $(7 \%)$. The majority of patients with tracheotomy (63\%) required a tube change every 16-30 days.

The medical professionals at the reference center were named as the primary provider for home ventilation management. However, only $48 \%$ of children required home health care, mostly those needing invasive ventilation for $\geq 12$ hours daily $\left(\chi_{\mathrm{MH}}^{2}=46\right.$; $\left.\mathrm{P}<<0.001\right)$ (Table 1). Parents were identified as the first care giver for all the children, and in 171 cases (47\%), the sole care giver. Other care givers were different professionals (40\% of children), family friends ( $8 \%)$, and non professional volunteers $(3 \%)$.

Pulse oximetry (saturation) was used as monitoring modality. Cardiovascular/respiratory lead monitoring was done in $10 \%$ of patients, particularly younger children $(\leq 5$ year age $)$, receiving non-invasive ventilation, and with neuromuscular disorders.

Multivariate logistic regression showed that invasive ventilation was likely associated with age of children - younger patients- (odds ratio [OR] 0.91; 95\% confidence interval [CI] 0.84-0.97), residence in the south of Italy (OR 2.94; CI 1.32-6.55), more years spent in mechanical ventilation (OR 1.33; CI 1.19-1.47), health care received at home (OR 8.02; CI 3.82-16.84), mechanical 
ventilation $\geq 12$ hours daily under (OR 11.65; CI 5.92-22.95), or neuromuscular disorder (OR 4.45; CI 1.13-17.62) or hypoxic (ischemic) encephalopathy (OR 3.62; CI 1.37-9.55).

\section{DISCUSSION}

This is the first report about children receiving long-term home ventilation in Italy. Approximately 4 per 100.000 children up to 17 years old had chronic mechanical respiratory support at home in 2007 , in good agreement with estimates from other countries. ${ }^{12,14,21}$ If the figures are generalized to the whole country, a total 404 children in Italy would be found, supporting the reliability of the present survey involving 362 children. Thus, even if the reported findings do not include all possible cases, they do provide the best available information for this group of children. Patients were resident in 75 of the 107 Italian provinces (70\%), and were mainly discharged from centers in the North of Italy, which may be attributed to fewer pediatric services in the South, in terms of quality and quantity. ${ }^{23}$ Health inequalities in childhood can lead to distress for the patient and the family, as well as financial waste. Thus, for this group of patients the burden of care is higher for southern residents.

The median length of home ventilation was one year, indicating that hospital discharge of these patients is a recent practice in Italy. In line with surveys from other countries ${ }^{9,12,16,21}$ neuromuscular disorders were the most frequent indication for long-term home ventilation, as the established supportive therapy reduces the morbidity and mortality of these children. ${ }^{24-28}$

Non-invasive support was used in the majority of the investigated population (59\%) and was more prevalent in later infancy and adolescence. This finding is consistent with the literature ${ }^{29}$ which identifies NIV as the preferred ventilation strategy and recommended IV only if required (i.e., inability to swallow, to cooperate, to clear airway secretions). Although, improvements in the technical features of mechanical ventilators and non-invasive interfaces have made a larger proportion of the pediatric population, including very young or small children, suitable for non- 
invasive mechanical ventilation, the prevalence of non-invasive ventilation in late childhood and adolescence probably reflects the better cooperation by older children. ${ }^{24,25}$ However, the paucity of non-invasive interfaces suitable for small children continues to be an important consideration that guides the choice of approach.

Invasive ventilation was significantly related not only to young age, but also to residence in the south, longer time spent under mechanical ventilation, and neuromuscular disorders or hypoxic (ischemic) encephalopathy. Inability to cooperate, to clear airway secretions, and to swallow are more common in neurological disorders and in younger children, and are contraindications to using non-invasive ventilation. ${ }^{29,30}$ The survey showed that children affected by neurological disorders provide the vast majority of patients receiving ventilation via tracheotomy. This finding is consistent with the results of Eurovent study. ${ }^{3}$ According to criteria proposed by Australasian consensus statement children requiring invasive ventilation spent longer time per day under mechanical ventilation. ${ }^{31}$ Regional differences in the type of ventilation reflect the health, social and organizational conditions and the medical staff expertise in the different settings. In fact, in the South of Italy, the vast majority of patients was discharged from pediatric intensive care units.

While NIV is generally accepted to support patients affected by Duchenne muscular dystrophy and SMA type $2,{ }^{27,32}$ the use of NIV for children with SMA type 1 is less clear and respiratory management differs around the world. ${ }^{33}$ The benefits and the burdens of both NIV and IV in children affected by SMA type 1 have to be again adequately evaluate. ${ }^{34}$ Different views and attitudes have the clinicians recommending/offering the type of ventilation to the parents of children with SMA type $1 .^{35,36}$ Findings suggest that in Italy both NIV and IV are used in this population at a similar rate, and further efforts are needs defining appropriate decisions.

One of the most surprising findings of the survey is the relatively high prevalence of children affected by encephalopathy supported with HMV. This finding is consistent with the results of an other Italian study. ${ }^{10}$ However, recent surveys documented that in other countries these patients 
don't represent one of the most important disorder categories of HMV children. ${ }^{9,18,21,22}$ Moreover, this study showed differences also in the type of interface used to ventilate these children. While in the United Kingdom NIV is usually preferred, ${ }^{37}$ in Italy the majority of children affected by encephalopathy is invasively ventilated. Both these differences are probably due to a different ethical approach around the world.

The main people involved in home ventilation surveys in $\mathrm{UK}^{18}$ and Massachusetts ${ }^{22}$ are pediatric pulmonologists and general pediatricians, and pediatric intensive care physicians are seldom involved (11\% and $1 \%$ of children respectively). In the present survey the majority of patients (59\%) were discharged from pediatric intensive care units or pediatric pulmonary units, suggesting a different attitude and involvement of Italian general pediatricians in the management of these patients compared to other countries.

As expected, ${ }^{22,38}$ pulse oximetry was the preferred monitoring modality at home, during noninvasive and invasive ventilation, particularly for children with neuromuscular disorders. This approach is in agreement with the regimen for managing acute and chronic neuromuscular respiratory failure at home described by Bach and colleagues. ${ }^{24}$

Similarly to French survey ${ }^{9}$ follow up was performed during outpatient visits in $60 \%$ of the patients. Records of arterial blood gases, nocturnal pulse oximetry and sleep study were the most common applied tests during routine follow up. This finding is consistent with the French study. ${ }^{9}$

In our study population uncuffed tracheotomy tubes are preferred over cuffed tubes. This finding is consistent with the literature. In fact, the indication for cuffed tracheotomy tubes are limited (i.e., patients with chronic translaryngeal aspiration, patients requiring ventilation with high pressures). ${ }^{39}$ There is no consensus regarding the frequency of tracheotomy tube changes. While recommended tube change frequency ranges from daily to monthly, the most common frequency is weekly. ${ }^{39}$ According to the literature, the frequency of tracheotomy tube changes in our population varies widely. However, the majority of patients required a tube change every 16-30 days. According to 
the literature, in most cases the tube change is performed by the caregiver. In fact, before the home discharge, caregivers should be trained in the replacement of tracheotomy tubes. ${ }^{39}$

The majority of patients that required home health care need invasive ventilation for more than 12 hours. This finding is consistent with criteria recommended by Australasian consensus statement. ${ }^{31}$ In fact, these children require high level of care and close supervision, which families are unable to sustain without assistance.

Heavy workload, loss of personal time, financial, and emotional resources are the main burden of care related to home care ventilation, falling on parents who, in at least half the cases met all their child's medical needs themselves. Both the hospital discharge and home care need adequate and appropriate approaches. Children with chronic ventilation at home need a coordinated multidisciplinary approach by trained and accountable professionals, parents, and lay people, based on interactions between different teams from the hospital, community, family, and carers. ${ }^{18,40-42}$ In our country specific state programs for pediatric home-care are devoted only to children affected by HIV or cystic fibrosis, while a program of respiratory home care for children with chronic respiratory failure have not yet been realized. Specific health care plan is already present only in selected regions. ${ }^{10,11}$

There are several limitations to the present survey. Although some children may have been excluded, the data from many different hospital providers give a comprehensive figure of the use of home mechanical ventilation in pediatric patients in Italy. No attempt was made to collect data retrospectively to describe the number of children previously ventilated at home or who either died or were weaned from the ventilator, or switched from invasive to non-invasive ventilation. This will be one of the topics of future investigations. Families' desires and acceptance of home mechanical ventilation may be different, and can be influenced by several reasons and factors that have to be evaluated to guide and support the discharge home. An Italian national ventilator program, and a 
national registry of home-ventilated children could help in monitoring and improving the care of these children (and their families) throughout the country.

In conclusion, the present survey provides, for the first time, reliable estimates of the prevalence of children receiving home mechanical ventilation in Italy. The majority of children are noninvasively ventilated. Invasive ventilation is significantly related to younger age, regional residence, more hours on ventilation and diagnosis (i.e., neurological disorders). Further work is needed to promote health program to monitor and improve the wellbeing of these children. However, this is a recognized challenge and technical and political commitments are necessary to provide the needed resources for patients and their families. 


\section{References}

1. Murphy J. Medically stable children in PICU: better at home. Paediatr Nurs. 2008;20(1):1416.

2. Herouvin L. From hospital to home for technology-dependent children. Paediatr Nurs. 2007;19(2):34.

3. Lloyd-Owen SJ, Donaldson GC, Ambrosino N, et al. Patterns of home mechanical ventilation use in Europe: results from the Eurovent survey. Eur Respir J. 2005;25:10251031.

4. Dhillon J, Frewen T, Singh N, Speechley K. Chronic mechanical dependent children in Canada. J Paediatr Child Health 1996;1:111-16.

5. Carnevale FA, Alexander E, Davis M, Rennick J, Troini R. Daily living with distress and enrichment: the moral experience of famiglie with ventilator-assisted children at home. Pediatrics 2006; 117: e48-e60.

6. Bertrand P, Fehlmann E, Lizama M, Holmgren N, Silva M, Sánchez I. Home ventilatory assistance in Chilean children: 12 years' experience. Arch Bronconeumol. 2006;42(4):16570.

7. Lang M, Schwering MS, Schöber JG. Practical experiences with home ventilation in childhood][Article in German] Med Klin (Munich). 1995;90(1 Suppl 1):52-6.

8. Fauroux B, Sardet A, Foret D. Home treatment for chronic respiratory failure in children: A prospective study. Eur Respir J. 1995;8(12):2062-6.

9. Fauroux B, Boffa C, Desguerre I, Estournet B, Trang H. Long-term noninvasive mechanical ventilation for children at home: A national survey. Pediatr Pulmonol. 2003;35(2):119-25.

10. Appierto L, Cori M, Bianchi R et al. Home care for chronic respiratory failure in children: 15 years experience. Paediatr Anaesth. 2002; 12 (4): 345-50.

11. Ottonello G, Ferrari I, Pirroddi IM, et al. Home mechanical ventilation in children: retrospective survey of a pediatric population. Pediatr Int. 2007;49(6):801-5.

12. Sakakihara Y, Yamanaka T, Kajii M, Kamoshita S. Long-term ventilator-assisted children in Japan: a national survey. Acta Paediatr Jpn. 1996;38(2):137-142.

13. Edwards EA, Hsiao K, Nixon GM. Paediatric home ventilatory support: the Auckland experience. J Paediatr Child Health. 2005;41(12):652-8.

14. Kamm M, Burger R, Rimensberger P, Knoblauch A, Hammer J. Survey of children supported by long-term mechanical ventilation in Switzerland. Swiss Med Wkly. 2001;131(19-20):261-6.

15. Goorhuis J.F., Cobben N.A.M., Van Der Voort E., Kampelmacher M.J. Structure and organization of the Center for Home Mechanical Ventilation for children in the Netherlands. Tijdschrift voor Kindergeneeskunde. 2009;77(3): 99-103.

16. Oktem S, Ersu R, Uyan ZS, et al. Home ventilation for children with chronic respiratory failure in Istanbul. Respiration. 2008;76(1):76-81.

17. Robinson RO. Ventilator dependency in the United Kingdom. Arch Dis Child. 1990;65(11):1235-6.

18. Jardine E, O'Toole M, Paton JY, Wallis C. Current status of long term ventilation of children in the United Kingdom: questionnaire survey. BMJ. 1999;318(7179):295-9. 
19. Edwards EA, O'Toole M, Wallis C. Sending children home on tracheostomy dependent ventilation: Pitfalls and outcomes. Arch Dis Child. 2004;89:251-5.

20. Goldberg AI, Frownfelter D. The ventilator-assisted individuals study. Chest. 1990; 98(2):428-433.

21. Gowans M, Keenan HT, Bratton SL. The population prevalence of children receiving invasive home ventilation in Utah. Pediatr Pulmonol. 2007;42(3):231-236.

22. Graham RJ, Fleegler EW, Robinson WM. Chronic Ventilator Need in the Community: A 2005 Pediatric Census of Massachusetts. Pediatrics. 2007; 119: e1280 - e1287.

23. Bonati M, Campi R What can we do to improve child health in Southern Italy? PLoS Med. 2005;2: e250.

24. Bach JR, Rajaraman R, Ballanger F, Tzeng AC, Ishikawa $Y$, Kulessa $R$ et al. Neuromuscular ventilatory insufficiency: Effect of home mechanical ventilator use vs oxygen therapy on pneumonia and hospitalization rates. Am J Phys Med Rehabil. 1998;77(1):8-19.

25. Tzeng AC, Bach JR. Prevention of pulmonary morbidity for patients with neuromuscular disease. Chest 2000;118(5):1390-6.

26. Gomez-Merino E, Bach JR. Duchenne Muscolar Dystrophy: prolongation of life by Noninvasive Ventilation and Mechanically assisted coughing. Am J Phys Med Rehabil. 2002;81(6):411-5.

27. Simonds AK, Ward S, Heather S, Bush A, Muntoni F. Outcome of paediatric domiciliary mask ventilation in neuromuscular and skeletal disease. Eur Resp J 2000; 16(3):476-81.

28. Sritippayawan S, Kun SS, Keens TG, Ward SL. Initiation of home mechanical ventilation in children with neuromuscular diseases. J Pediatr 2003; 142:481-5.

29. Mehta S and Hill NS. State of the Art: Non-invasive Ventilation. Am J Respir Crit Care Med. 2001;163: 540-577.

30. Make BJ, Hill NS, Goldberg AI, Bach JR, Criner GJ, Dunne PE, Gilmartin ME, Heffner JE, Kacmarek R, Keens TG, McInturff S, O'Donohue WJ Jr, Oppenheimer EA, Robert D. Mechanical ventilation beyond the intensive care unit. Report of a consensus conference of the American College of Chest Physicians. Chest. 1998;113(5 Suppl):289S-344S.

31. The Thoracic Society of Australia and New Zealand. Ventilatory support at home for children. A consensus statement for the Australasian paediatric respiratory group. 2008: http://www.thoracic.org.au/documents/papers/aprghomeventilationguideline.pdf.

32. Katz S, Selvadurai H, Keilty K, Mitchell M, MacLusky I. Outcome of non-invasive positive pressure ventilation in paediatric neuromuscular disease. Arch Dis Child 2004;89(2):121-4.

33. Wang CH, Finkel RS, Bertini ES, Schroth M, Simonds A, Wong B, Aloysius A, Morrison L, Main M, Crawford TO, Trela A; Participants of the International Conference on SMA Standard of Care. Consensus statement for standard of care in spinal muscular atrophy. $J$ Child Neurol 2007;22(8):1027-49.

34. Tobin B. Editorial overview: is the use of invasive ventilation is appropriate in children with genetically proven muscular atrophy type I? Paediatric Respiratory Reviews 2008; 9:55-56.

35. Bach JR. The use of mechanical ventilation is appropriate in children with genetically proven muscular atrophy type I: the motion for. Paediatric Respiratory Reviews 2008; 9:4550.

36. Ryan MM.. The use of invasive ventilation is appropriate in children with genetically proven muscular atrophy type I: the motion against. Paediatric Respiratory Reviews 2008; 9:51-54.

37. Simonds AK Respiratory support for the severely handicapped child with neuromuscular disease: ethics and practicality. Semin Respir Crit Care Med 2007; 28:342-54. 
38. Profit J, McCormick MC, Escobar GJ, Richardson DK, Zheng Z, Coleman-Phox K, Roberts R, Zupancic JAF. Neonatal Intensive Care Unit Census Influences Discharge of Moderately Preterm Infants. Pediatrics. 2007; 119:314-319.

39. Sherman JM, Davis S, Albamonte-Petrick S, Chatburn RL, Fitton C, Green C et al. Care of the child with chronic tracheostomy. Am J Respir Crit Care Med. 2000;161(1):297-308.

40. Jardine E, Wallis C. Core guidelines for the discharge home of the child on long-term assisted ventilation in the United Kingdom. UK Working Party on Paediatric Long Term Ventilation. Thorax. 1998;53(9):762-7.

41. Perrin J, Erenberg G, LaCamera Rea. Guidelines for home care of infants, children, and adolescents with chronic disease. American Academy of Pediatrics Committee on Children with Disabilities. Pediatrics.1995;96(1Pt1):161-4.

42. Wang KW, Barnard A. Caregivers' experiences at home with a ventilator-dependent child. Qual Health Res. 2008;18(4):501-508. 
TABLE 1 Children's characteristics and type of ventilation

\begin{tabular}{|c|c|c|c|}
\hline Characteristics & $\begin{array}{c}\text { Invasive } \\
\text { ventilation }\end{array}$ & $\begin{array}{l}\text { Noninvasive } \\
\text { ventilation }\end{array}$ & Total \\
\hline No. of subjects & 149 & 213 & 362 \\
\hline Male/female, $n$ & $87 / 62$ & $116 / 97$ & $203 / 159^{\mathrm{al}}$ \\
\hline \multicolumn{4}{|l|}{ Area of residence ${ }^{b}$} \\
\hline Northern Italy & 84 & 115 & 199 \\
\hline Central Italy & 21 & 35 & 56 \\
\hline Southern Italy & 44 & 63 & 107 \\
\hline Age, median (interquartile range), $y$ & $6(3-9)$ & $11(5-15)$ & $8(4-14)^{\mathrm{cI}}$ \\
\hline \multicolumn{4}{|l|}{ Age at start of mechanical ventilation } \\
\hline median (interquartile rage), $y$ & $1(0-4)$ & $8(3-13)$ & $4(1-11)^{\mathrm{c} 2}$ \\
\hline \multicolumn{4}{|l|}{ Time on ventilation support } \\
\hline median (interquartile range), $y$ & $3(1-5)$ & $1(0-2)$ & $1(0-4)^{\mathrm{c} 3}$ \\
\hline \multicolumn{4}{|l|}{ Major diagnostic category ${ }^{\mathrm{d}}, n$} \\
\hline Neuromuscular disorders & 66 & 112 & 178 \\
\hline Chronic lung and upper respiratory diseases & 12 & 52 & 64 \\
\hline Hypoxic (ischemic) encephalopathy & 31 & 17 & 48 \\
\hline Abnormal ventilation control & 25 & 19 & 44 \\
\hline Spinal cord injury & 10 & 1 & 11 \\
\hline Chest anomalies & 4 & 12 & 16 \\
\hline Other & 1 & 0 & 1 \\
\hline \multicolumn{4}{|l|}{ Hours/day spent under mechanical ventilation } \\
\hline$<12 / \geq 12, n$ & $29 / 120$ & $178 / 35$ & $207 / 155^{\mathrm{a} 2}$ \\
\hline \multicolumn{4}{|l|}{ Ventilation monitoring modality, $n$} \\
\hline Pulse oximetry (saturation) & 136 & 144 & 280 \\
\hline Cardiovascular/respiratory leads & 8 & 29 & 37 \\
\hline
\end{tabular}




\begin{tabular}{|l|c|c|c|}
\hline End tidal $\mathrm{CO}_{2}$ & 11 & 0 & 11 \\
\hline None & 3 & 38 & 41 \\
\hline Other & 4 & 3 & 7 \\
\hline Home health care, yes/no, $n$ & $121 / 28$ & $51 / 162$ & $172 / 190^{\mathrm{a} 3}$ \\
\hline
\end{tabular}

${ }^{\mathrm{a} 1}: \chi^{2}=0.55 ; \mathrm{P}>0.459 ;{ }^{\mathrm{a} 2}: \chi^{2}=148 ; \mathrm{P}<<0.001 ;{ }^{\mathrm{a} 3}: \chi^{2}=115 ; \mathrm{P}<<0.001$

${ }^{\mathrm{b}}: \chi_{\text {trend }}^{2}=0.07 ; \mathrm{P}>0.80$

${ }^{\mathrm{c}}$ Mann-Whitney U test: ${ }^{\mathrm{c} 1}=-6.147 ; \mathrm{P}<<0.001 ;{ }^{\mathrm{c} 2}:=-8.733 ; \mathrm{P}<<0.001 ;{ }^{\mathrm{c} 3}=5.873 ; \mathrm{P}<<0.001$

${ }^{\mathrm{d}}: \mathrm{F}=5.94 ; \mathrm{P}<0.016$ 


\section{Long-term Home Ventilation of Children in Italy: a National Survey}

F. Racca ${ }^{a}$ G. Berta ${ }^{a}$ M. Sequi ${ }^{\text {b }}$ E. Bignamini ${ }^{\mathrm{c}}$ E. Capello $^{\mathrm{a}}$ R. Cutrera ${ }^{\mathrm{d}}$ G. Ottonello ${ }^{\mathrm{e}}$ V.M. Ranieri $^{a}$ I. Salvo ${ }^{f}$ R. Testa ${ }^{g}$ A. Wolfler ${ }^{f}$ and M. Bonati" on behalf of the "LTV Pediatric Italian Network"

${ }^{a}$ Department of Anesthesiology and Intensive Care Medicine, San Giovanni Battista-Molinette Hospital, University of Turin, Turin, Italy.

${ }^{b}$ Laboratory for Mother and Child Health, Department of Public Health,

"Mario Negri" Pharmacological Research Institute, Milan, Italy

c Pulmonology Unit, Regina Margherita University Children's Hospital, Turin, Italy

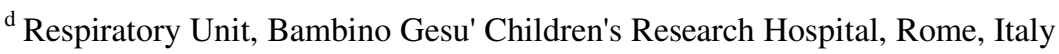

${ }^{\mathrm{e}}$ Anesthesiology and Intensive Care Medicine Unit, G. Gaslini Institute, Genoa, Italy

${ }^{\mathrm{f}}$ Department of Anesthesiology and Intensive Care, Vittore Buzzi Children's Hospital, Milan, Italy

${ }^{\mathrm{g}}$ Intensive Care Unit, Santobono Hospital, Naples, Italy

hLTV Pediatric Italian Network": Anna Costantino, Alessandria; Raffaella Pagni, Ancona; Anna Maria Miorelli, Arco; Paolo Castaldi, Cagliari; Mariano Cabras, Carbonia; Bruno Dengo, Castelfranco Veneto; Augusto Biasini, Cesena; Francesco Morandi, Erba; Carlo Minetti, Giancarlo Ottonello, Genova; Paolo Banfi, Maurizio Bonati, Edoardo Calderini, Edi Prandi, Ida Salvo, Marco Sequi, Andrea Wolfler, Marco Zucconi, Milano; Giuseppe Fiorentino, Antonio Maddalena, Raffaele Testa, Napoli; Grazia Crescimanno, Anna Guddo, Palermo; Livio Carnevale, Pavia; Andrea Vianello, Padova; Giancarlo Piccinini, Ravenna; Valter Bottari, Reggio Emilia; Maurizio Corbari, Renato Cutrera, Martino Pavone, Roma; Giacomo Berta, Elisabetta Bignamini, Elena Capello, Lorenzo Del Sorbo, Cesare Gregoretti, Maria Maspoli, Fabrizio Racca, Marco V. Ranieri, Torino; Antonio Peratoner, Udine; Monica Benedetti, Verona.

Address correspondence to:

Maurizio Bonati, MD

Head of Department of Public Health and of the

Laboratory for Mother and Child Health

"Mario Negri" Pharmacological Research Institute

Via Giuseppe La Masa 19, 20156

Milan, Italy

Tel 00390239014.511

Fax 0039023550924

Email: mother_child@marionegri.it

Funding: none

Short title: Home Mechanical Ventilation for Italian Children 
Keywords: Chronic respiratory failure, home respiratory care, long term ventilation, home mechanical ventilation, epidemiology, artificial ventilation, disability.

| Word count: 3019

Deleted: 2962

Number of figures: 0

Conflicts of interest: none. 


\begin{abstract}
Background: Improved technology, as well as professional and parental awareness, enable many ventilator-dependent children to live at home. However, the profile of this growing population, the quality and adequacy of home care, and patients' needs still require thorough assessment.
\end{abstract}

Objectives: To define the characteristics of Italian children receiving long-term home mechanical ventilation (HMV) in Italy.

Methods: A detailed questionnaire was sent to 302 National Health Service hospitals potentially involved in the care of HVM in children (aged $<17 \mathrm{yrs}$ ). Information was collected on patient characteristics, type of ventilation, and home respiratory care.

Results: A total of 362 HMV children was identified. The prevalence was 4.2 per 100,000 (95\% CI: 3.8-4.6), median age was 8 years (interquartile range 4-14), median age at starting mechanical ventilation was 4 years (1-11), and 56\% were male. The most frequent diagnostic categories were neuromuscular disorders (49\%), lung and upper respiratory tract diseases (18\%), hypoxic (ischemic) encephalopathy (13\%), and abnormal ventilation control (12\%). Medical professionals with nurses (for $62 \%$ of children) and physiotherapists ( $20 \%$ ) participated in the patients' discharge from hospital, though parents were the primary care give, $r$ and in $47 \%$ of cases, the sole care giver. Invasive ventilation was used in $41 \%$ and was significantly related to young age, southern regional residence, longer time spent under mechanical ventilation, neuromuscular disorders, or hypoxic (ischemic) encephalopathy.

Conclusions: Care and technical assistance of long-term HMV children need assessment, planning, and resources. A wide variability in pattern of HMV was found throughout Italy. An Italian national ventilation program, as well as a national registry, could be useful in improving the care of these often critically ill children. 


\section{INTRODUCTION}

Continuous advances in neonatal and pediatric intensive care are likely to result in more infants, children, and adolescents with critical, chronic conditions, who survive and who are discharged home, but require long-term technological support. ${ }^{1-3}$ A growing population of children exists who has chronic respiratory failure due to conditions such as neuromuscular diseases, obstructive sleep apnea, craniofacial abnormalities, or spinal cord injuries, and who require either tracheostomy or mask ventilation.

Pressure to reduce the hospital stay of these children and awareness of the effects of long termhospitalization on a child's development have, during the last decade - especially, in a few countries such as UK, France, and US, - increased the numbers of ventilated children discharged home. However, the availability and practical details of complex respiratory support at home involve a lot of variables such as appropriate home environment, healthcare support, and funding, that cannot always be guaranteed. Findings of the Eurovent study, a wide cross sectional survey including adults as well as children, highlighted how the collection of information about home mechanical ventilation (HMV) could facilitate national planning for HMV. In particular, it could aid the development of HMV services in order to ensure equality of provision and access. ${ }^{3}$ Surveys in Canada, ${ }^{4,5}$ Chile, ${ }^{6}$ Germany, ${ }^{7}$ France,${ }^{8,9}$ Italy, ${ }^{10,11}$ Japan, ${ }^{12}$ New Zealand, ${ }^{13}$ Switzerland, ${ }^{14}$ The Netherlands, ${ }^{15}$ Turkey, ${ }^{16}$ UK, ${ }^{17-19}$ and $\mathrm{USA}^{20-}{ }_{-} 2$ have defined the size, main features, and needs of the pediatric population requiring home mechanical ventilation. However there are many differences between these observational studies: the setting (single referring center, state, or country), the time period (one year or trend over time), the data collected, and how it was collected. Thus, estimates of the national prevalence of home ventilator-dependent children range from $0.7 / 100,000$ children in 1993 in Japan ${ }^{12}$ to 3.4/100,000 in 2000 in Switzerland. ${ }^{14}$ Because information on long-term home ventilation for children in Italy is scant and erratic (no regional or national population-based data exist), this survey was conducted to describe the size and 
characteristics of the pediatric Italian population receiving chronic mechanical ventilation at home and the profile of home respiratory care.

\section{METHODS}

\section{Study Population}

A questionnaire was sent to all 27 Italian pediatric intensive care and pulmonary units to get data on children up to 17 years old receiving HMV in January 2007. To identify as many children as possible the questionnaire was sent also to another 275 hospital-based units (eg. pulmonary services, and critical care units) of the National Health Service (NHS) that are potentially involved in the care of the target population. Information referred to children discharged home from hospital whorequired tracheostomy or mask ventilation.

\section{Home respiratory care}

HMV was defined as invasive mechanical ventilation (IMV) or non invasive mechanical ventilation (NIV), for a period of at least 3 months on a daily basis, carried out mostly in the user's home or other long-term care facility (not a hospital). ${ }^{3}$ Basic demographic data (age, sex, place of residence), causes of respiratory failure, hospitalization history, duration of ventilatory support, type of ventilation and management-related description and home care provider information were collected.

\section{Data analysis}

Data were entered into a SAS/STAT database (Statistical Analysis Software, Cary, NC) for recording and analysis. The prevalence with $95 \%$ confidence intervals (CI) of Italian children ventilated at home on the long term was calculated using the Istat 2007 annual report (Italian National Institute of Statistics) for children up to 17 years old, resident in the provinces in which patients were identified as the denominator. Age was calculated on the basis of the date of birth and the date of onset of ventilation was recorded. 
Descriptive statistics were computed for the entire study population and subgroups. Student's $t$ test was used to compare the type of ventilation and patient's age (continuous variable). $\chi^{2}$ tests were used to compare the type of ventilation and categorical variables, such as sex and home health care. The Mann-Whitney U test was used to compare the type of ventilation in each class of time/day spent under mechanical ventilation. ANOVA was used to check the association between the type of ventilation and class of diagnosis. Comparisons of the type of ventilation in each region were tested by $\chi_{\text {trend }}^{2}$ analysis. Multivariate logistic regression was used to look at the association between the type of ventilation and all monitored factors, simultaneously.

Results are presented as frequencies, or median and interquartile range; $\mathrm{P}<0.05$ was considered significant.

All data collected on centres and patients were kept strictly confidential. Data on patients were anonymous. The San Giovanni Battista-Molinette Hospital, University of Turin, Committee on Clinical Investigation reviewed and approved the study protocol. Because this was an observational study without an intervention and without the presentation of any identifying data, the committee ruled that informed consent was not necessary.

\section{RESULTS}

A total of 362 children were identified by 30 centers (67\% in the North of Italy) as receiving home mechanical ventilation in January 2007, with an estimated prevalence of 4.2 per $100,000 \leq 17$ year old children (95\% CI 3.8-4.6). Patients were resident in 75 of the 107 Italian provinces (70\%); 200 $(55 \%)$ were resident in the North, $55(15 \%)$ in the Center, and $107(30 \%)$ in the South, in good agreement with the national distribution of children up to 17 years old. No difference was observed between the type of ventilation and the area of residence (Table 1). The majority of patients (59\%) were discharged from 12 of 27 NHS pediatric intensive care units or pediatric pulmonary units that were following mechanically ventilated children at home, and the others came from 18 other 
hospital units and wards (i.e., adult intensive care units, adult pulmonary units, pediatric neurology units, pediatric palliative care units). The median number of children followed by each center was seven (interquartile range 3-19).

The median age was 8 years (interquartile range 4-14) and was significantly different for children receiving invasive or non-invasive ventilation $(\mathrm{P}<<0.001)$, as well as for the median age at the start of mechanical ventilation $(\mathrm{P}<<0.001)$ (Table 1). All children received positive pressure ventilation. The majority of children receives NIV (Table 1), which is delivered mostly by nasal mask (85\% of patients receiving NIV). Non-invasive ventilator support was the most used and skewed toward late infancy and adolescence.. Overall, $41 \%$ of the survey population had ventilation via tracheotomy with the highest percentage of children affected by neurological disorders. The median duration of home mechanical ventilation was one year (Table 1).

The most frequent diagnostic category was neuromuscular disorders (49\%), followed by lung and upper respiratory diseases (18\%), hypoxic (ischemic) encephalopathy (13\%), and abnormal ventilation control (12\%) (Table 1). The most represented neuromuscular disorders were spinal muscular atrophy (SMA) (78 patients), Duchenne muscular dystrophy (31 patients) and Congenital muscular dystrophy (29 patients). In particular, 25 children were affected by SMA type 1 (16 receiving NIV, 64\%) and 53 children by SMA type 2 (30 receiving NIV, $57 \%$ ).

Deleted: 80
Deleted: )
Deleted: 32
Deleted: 31
Deleted: 24
Deleted: 56
There were wide difference between the type of ventilation and diagnoses $(\mathrm{F}=5.94, \mathrm{P}<0.016)$. Time per day spent under mechanical ventilation was longer for children requiring invasive ventilation $\left(\chi^{2}=148 ; \mathrm{P}<<0.001\right)$ (Table 1$)$, particularly for those with neuromuscular disorders $\left(\chi^{2}\right.$ $=73 ; \mathrm{P}<<0.001)$, hypoxic (ischemic) encephalopathy $\left(\chi^{2}=37\right.$; $\left.\mathrm{P}<<0.001\right)$, or chronic lung and upper respiratory diseases $\left(\chi^{2}=28 ; \mathrm{P}<<0.001\right)$. Nurses (for $62 \%$ of children), physiotherapists (20\%), social workers (7\%), psychologists (7\%), pediatricians $(5 \%)$, and other professionals $(4 \%)$ participated in the home discharge process with hospital physicians. All children were involved in a patient ventilator training program (94\% during 
inpatient visits; $6 \%$ during outpatient visits) and in a regular monitoring program. At home visits were planned in $60 \%$ of patients (36\% of patients only during planned hospitalization, $30 \%$ only during outpatient visits, $29 \%$ with both modalities, 5 and $\%$ only at home). The mean number of hospital visits was $2.8 /$ year, while the mean number of at home visits was $27 /$ year. The at home visit program involves general practitioners (63\% of patients), hospital physicians (65\% of patients), nurses (49\% of patients), physical therapists (22\% of patients). Arterial blood gases (59\% of patients), sleep study ( $41 \%$ of patients), and nocturnal pulse oximetry (33\% of patients), were the principal investigations during monitoring program.

The majority of children with a tracheotomy had uncuffed tube $(64,2 \%)$. The at home tracheotomy tube changes were performed by parents (39\% of tracheotomised patients), by intensivists (25\%), by nurses $(19 \%)$, by pulmonologists $(10 \%)$, or by others $(7 \%)$. The majority of patients with tracheotomy $(63 \%)$ required a tube change every 16-30 days.

The medical professionals at the reference center were named as the primary provider for home ventilation management. However, only $48 \%$ of children required home health care, mostly those needing invasive ventilation for $\geq 12$ hours daily $\left(\chi_{\mathrm{MH}}^{2}=46\right.$; $\left.\mathrm{P}<<0.001\right)$ (Table 1$)$. Parents were identified as the first care giver for all the children, and in 171 cases (47\%), the sole care giver. Other care givers were different professionals (40\% of children), family friends (8\%), and non professional volunteers $(3 \%)$.

Pulse oximetry (saturation) was used as monitoring modality. Cardiovascular/respiratory lead monitoring was done in $10 \%$ of patients, particularly younger children $(\leq 5$ year age), receiving non-invasive ventilation, and with neuromuscular disorders.

Multivariate logistic regression showed that invasive ventilation was likely associated with age of children - younger patients- (odds ratio [OR] 0.91; 95\% confidence interval [CI] 0.84-0.97), residence in the south of Italy (OR 2.94; CI 1.32-6.55), more years spent in mechanical ventilation (OR 1.33; CI 1.19-1.47), health care received at home (OR 8.02; CI 3.82-16.84), mechanical 
ventilation $\geq 12$ hours daily under (OR 11.65; CI 5.92-22.95), or neuromuscular disorder (OR 4.45; CI 1.13-17.62) or hypoxic (ischemic) encephalopathy (OR 3.62; CI 1.37-9.55).

\section{DISCUSSION}

This is the first report about children receiving long-term home ventilation in Italy. Approximately 4 per 100.000 children up to 17 years old had chronic mechanical respiratory support at home in 2007 , in good agreement with estimates from other countries. ${ }^{12,14,21}$ If the figures are generalized to the whole country, a total 404 children in Italy would be found, supporting the reliability of the present survey involving 362 children. Thus, even if the reported findings do not include all possible cases, they do provide the best available information for this group of children. Patients were resident in 75 of the 107 Italian provinces (70\%), and were mainly discharged from centers in the North of Italy, which may be attributed to fewer pediatric services in the South, in terms of quality and quantity. ${ }^{23}$ Health inequalities in childhood can lead to distress for the patient and the family, as well as financial waste. Thus, for this group of patients the burden of care is higher for southern residents.

The median length of home ventilation was one year, indicating that hospital discharge of these patients is a recent practice in Italy. In line with surveys from other countries ${ }^{9,12,16,21}$ neuromuscular disorders were the most frequent indication for long-term home ventilation, as the established supportive therapy reduces the morbidity and mortality of these children. ${ }^{24-28}$ Non-invasive support was used in the majority of the investigated population (59\%) and was more prevalent in later infancy and adolescence. This finding is consistent with the literature ${ }^{29}$ which identifies NIV as the preferred ventilation strategy and recommended IV only if required (i.e., inability to swallow, to cooperate, to clear airway secretions). Although, improvements in the technical features of mechanical ventilators and non-invasive interfaces have made a larger proportion of the pediatric population, including very young or small children, suitable for non- 
invasive mechanical ventilation, the prevalence of non-invasive ventilation in late childhood and adolescence probably reflects the better cooperation by older children. ${ }^{24,25}$ However, the paucity of non-invasive interfaces suitable for small children continues to be an important consideration that guides the choice of approach.

Invasive ventilation was significantly related not only to young age, but also to residence in the south, longer time spent under mechanical ventilation, and neuromuscular disorders or hypoxic (ischemic) encephalopathy. Inability to cooperate, to clear airway secretions, and to swallow are more common in neurological disorders and in younger children, and are contraindications to using non-invasive ventilation. ${ }^{29,30}$ The survey showed that children affected by neurological disorders provide the vast majority of patients receiving ventilation via tracheotomy. This finding is consistent with the results of Eurovent study. ${ }^{3}$ According to criteria proposed by Australasian consensus statement children requiring invasive ventilation spent longer time per day under mechanical ventilation. ${ }^{31}$ Regional differences in the type of ventilation reflect the health, social and organizational conditions and the medical staff expertise in the different settings. In fact, in the South of Italy, the vast majority of patients was discharged from pediatric intensive care units.

While NIV is generally accepted to support patients affected by Duchenne muscular dystrophy and SMA type $2,{ }^{27,32}$ the use of NIV for children with SMA type 1 is less clear and respiratory management differs around the world. ${ }^{33}$ The benefits and the burdens of both NIV and IV in children affected by SMA type 1 have to be again adequately evaluate. ${ }^{34}$ Different views and attitudes have the clinicians recommending/offering the type of ventilation to the parents of children with SMA type 1.35,36 Findings suggest that in Italy both NIV and IV are used in this population at $\underline{\text { a similar rate, and further efforts are needs defining appropriate decisions. }}$

One of the most surprising findings of the survey is the relatively high prevalence of children Formatted: Superscript

Formatted: Superscript

Deleted: Interestingly, the results of our study suggest that both NIV and IV are possible option for patients affected by SMA type 1 . affected by encephalopathy supported with HMV. This finding is consistent with the results of an other Italian study. ${ }^{10}$ However, recent surveys documented that in other countries these patients 
don't represent one of the most important disorder categories of HMV children. ${ }^{9,18,21,22}$ Moreover, this study showed differences also in the type of interface used to ventilate these children. While in the United Kingdom NIV is usually preferred, 37 in Italy the majority of children affected by encephalopathy is invasively ventilated. Both these differences are probably due to a different ethical approach around the world.

The main people involved in home ventilation surveys in $\mathrm{UK}^{18}$ and Massachusetts ${ }^{22}$ are pediatric pulmonologists and general pediatricians, and pediatric intensive care physicians are seldom involved (11\% and $1 \%$ of children respectively). In the present survey the majority of patients (59\%) were discharged from pediatric intensive care units or pediatric pulmonary units, suggesting a different attitude and involvement of Italian general pediatricians in the management of these patients compared to other countries.

As expected, ${ }^{22,38}$ pulse oximetry was the preferred monitoring modality at home, during noninvasive and invasive ventilation, particularly for children with neuromuscular disorders. This approach is in agreement with the regimen for managing acute and chronic neuromuscular respiratory failure at home described by Bach and colleagues. ${ }^{24}$ Similarly to French survey ${ }^{9}$ follow up was performed during outpatient visits in $60 \%$ of the patients. Records of arterial blood gases, nocturnal pulse oximetry and sleep study were the most common applied tests during routine follow up. This finding is consistent with the French study. ${ }^{9}$ In our study population uncuffed tracheotomy tubes are preferred over cuffed tubes. This finding is consistent with the literature. In fact, the indication for cuffed tracheotomy tubes are limited (i.e., patients with chronic translaryngeal aspiration, patients requiring ventilation with high pressures) ${ }^{39}$ There is no consensus regarding the frequency of tracheotomy tube changes. While recommended tube change frequency ranges from daily to monthly, the most common frequency is weekly. According to the literature, the frequency of tracheotomy tube changes in our population varies widely. However, the majority of patients required a tube change every 16-30 days. According to 
the literature, in most cases the tube change is performed by the caregiver. In fact, before the home discharge, caregivers should be trained in the replacement of tracheotomy tubes. ${ }^{39}$

The majority of patients that required home health care need invasive ventilation for more than 12 hours. This finding is consistent with criteria recommended by Australasian consensus statement. ${ }^{31}$ In fact, these children require high level of care and close supervision, which families are unable to sustain without assistance.

Heavy workload, loss of personal time, financial, and emotional resources are the main burden of care related to home care ventilation, falling on parents who, in at least half the cases met all their child's medical needs themselves. Both the hospital discharge and home care need adequate and appropriate approaches. Children with chronic ventilation at home need a coordinated multidisciplinary approach by trained and accountable professionals, parents, and lay people, based on interactions between different teams from the hospital, community, family, and carers. ${ }^{18,40-42}$ In our country specific state programs for pediatric home-care are devoted only to children affected by HIV or cystic fibrosis, while a program of respiratory home care for children with chronic respiratory failure have not yet been realized. Specific health care plan is already present only in selected regions. ${ }^{10,11}$

There are several limitations to the present survey. Although some children may have been excluded, the data from many different hospital providers give a comprehensive figure of the use of home mechanical ventilation in pediatric patients in Italy. No attempt was made to collect data retrospectively to describe the number of children previously ventilated at home or who either died or were weaned from the ventilator, or switched from invasive to non-invasive ventilation. This will be one of the topics of future investigations. Families' desires and acceptance of home mechanical ventilation may be different, and can be influenced by several reasons and factors that have to be evaluated to guide and support the discharge home. An Italian national ventilator program, and a 
1

national registry of home-ventilated children could help in monitoring and improving the care of these children (and their families) throughout the country.

In conclusion, the present survey provides, for the first time, reliable estimates of the prevalence of children receiving home mechanical ventilation in Italy. The majority of children are noninvasively ventilated. Invasive ventilation is significantly related to younger age, regional residence, more hours on ventilation and diagnosis (i.e., neurological disorders). Further work is needed to promote health program to monitor and improve the wellbeing of these children. However, this is a recognized challenge and technical and political commitments are necessary to provide the needed resources for patients and their families. 


\section{References}

1. Murphy J. Medically stable children in PICU: better at home. Paediatr Nurs. 2008;20(1):1416.

2. Herouvin L. From hospital to home for technology-dependent children. Paediatr Nurs. 2007;19(2):34.

3. Lloyd-Owen SJ, Donaldson GC, Ambrosino N, et al. Patterns of home mechanical ventilation use in Europe: results from the Eurovent survey. Eur Respir J. 2005;25:10251031.

4. Dhillon J, Frewen T, Singh N, Speechley K. Chronic mechanical dependent children in Canada. J Paediatr Child Health 1996;1:111-16.

5. Carnevale FA, Alexander E, Davis M, Rennick J, Troini R. Daily living with distress and enrichment: the moral experience of famiglie with ventilator-assisted children at home. Pediatrics 2006; 117: e48-e60.

6. Bertrand P, Fehlmann E, Lizama M, Holmgren N, Silva M, Sánchez I. Home ventilatory assistance in Chilean children: 12 years' experience. Arch Bronconeumol. 2006;42(4):16570.

7. Lang M, Schwering MS, Schöber JG. Practical experiences with home ventilation in childhood][Article in German] Med Klin (Munich). 1995;90(1 Suppl 1):52-6.

8. Fauroux B, Sardet A, Foret D. Home treatment for chronic respiratory failure in children: A prospective study. Eur Respir J. 1995;8(12):2062-6.

9. Fauroux B, Boffa C, Desguerre I, Estournet B, Trang H. Long-term noninvasive mechanical ventilation for children at home: A national survey. Pediatr Pulmonol. 2003;35(2):119-25.

10. Appierto L, Cori M, Bianchi R et al. Home care for chronic respiratory failure in children: 15 years experience. Paediatr Anaesth. 2002; 12 (4): 345-50.

11. Ottonello G, Ferrari I, Pirroddi IM, et al. Home mechanical ventilation in children: retrospective survey of a pediatric population. Pediatr Int. 2007;49(6):801-5.

12. Sakakihara Y, Yamanaka T, Kajii M, Kamoshita S. Long-term ventilator-assisted children in Japan: a national survey. Acta Paediatr Jpn. 1996;38(2):137-142.

13. Edwards EA, Hsiao K, Nixon GM. Paediatric home ventilatory support: the Auckland experience. J Paediatr Child Health. 2005;41(12):652-8.

14. Kamm M, Burger R, Rimensberger P, Knoblauch A, Hammer J. Survey of children supported by long-term mechanical ventilation in Switzerland. Swiss Med Wkly. 2001;131(19-20):261-6.

15. Goorhuis J.F., Cobben N.A.M., Van Der Voort E., Kampelmacher M.J. Structure and organization of the Center for Home Mechanical Ventilation for children in the Netherlands. Tijdschrift voor Kindergeneeskunde. 2009;77(3): 99-103.

16. Oktem S, Ersu R, Uyan ZS, et al. Home ventilation for children with chronic respiratory failure in Istanbul. Respiration. 2008;76(1):76-81.

17. Robinson RO. Ventilator dependency in the United Kingdom. Arch Dis Child. 1990;65(11):1235-6.

18. Jardine E, O'Toole M, Paton JY, Wallis C. Current status of long term ventilation of children in the United Kingdom: questionnaire survey. BMJ. 1999;318(7179):295-9. 
19. Edwards EA, O’Toole M, Wallis C. Sending children home on tracheostomy dependent ventilation: Pitfalls and outcomes. Arch Dis Child. 2004;89:251-5.

20. Goldberg AI, Frownfelter D. The ventilator-assisted individuals study. Chest. 1990; 98(2):428-433.

21. Gowans M, Keenan HT, Bratton SL. The population prevalence of children receiving invasive home ventilation in Utah. Pediatr Pulmonol. 2007;42(3):231-236.

22. Graham RJ, Fleegler EW, Robinson WM. Chronic Ventilator Need in the Community: A 2005 Pediatric Census of Massachusetts. Pediatrics. 2007; 119: e1280 - e1287.

23. Bonati M, Campi R What can we do to improve child health in Southern Italy? PLoS Med. 2005;2: e250.

24. Bach JR, Rajaraman R, Ballanger F, Tzeng AC, Ishikawa Y, Kulessa R et al. Neuromuscular ventilatory insufficiency: Effect of home mechanical ventilator use vs oxygen therapy on pneumonia and hospitalization rates. Am J Phys Med Rehabil. 1998;77(1):8-19.

25. Tzeng AC, Bach JR. Prevention of pulmonary morbidity for patients with neuromuscular disease. Chest 2000;118(5):1390-6.

26. Gomez-Merino E, Bach JR. Duchenne Muscolar Dystrophy: prolongation of life by Noninvasive Ventilation and Mechanically assisted coughing. Am J Phys Med Rehabil. 2002;81(6):411-5.

27. Simonds AK, Ward S, Heather S, Bush A, Muntoni F. Outcome of paediatric domiciliary mask ventilation in neuromuscular and skeletal disease. Eur Resp $J$ 2000; 16(3):476-81.

28. Sritippayawan S, Kun SS, Keens TG, Ward SL. Initiation of home mechanical ventilation in children with neuromuscular diseases. J Pediatr 2003; 142:481-5.

29. Mehta S and Hill NS. State of the Art: Non-invasive Ventilation. Am J Respir Crit Care Med. 2001;163: 540-577.

30. Make BJ, Hill NS, Goldberg AI, Bach JR, Criner GJ, Dunne PE, Gilmartin ME, Heffner JE, Kacmarek R, Keens TG, McInturff S, O'Donohue WJ Jr, Oppenheimer EA, Robert D. Mechanical ventilation beyond the intensive care unit. Report of a consensus conference of the American College of Chest Physicians. Chest. 1998;113(5 Suppl):289S-344S.

31. The Thoracic Society of Australia and New Zealand. Ventilatory support at home for children. A consensus statement for the Australasian paediatric respiratory group. 2008: http://www.thoracic.org.au/documents/papers/aprghomeventilationguideline.pdf.

32. Katz S, Selvadurai H, Keilty K, Mitchell M, MacLusky I. Outcome of non-invasive positive pressure ventilation in paediatric neuromuscular disease. Arch Dis Child 2004;89(2):121-4.

33. Wang CH, Finkel RS, Bertini ES, Schroth M, Simonds A, Wong B, Aloysius A, Morrison L, Main M, Crawford TO, Trela A; Participants of the International Conference on SMA Standard of Care. Consensus statement for standard of care in spinal muscular atrophy. $J$ Child Neurol 2007;22(8):1027-49.

34. Tobin B. Editorial overview: is the use of invasive ventilation is appropriate in children with genetically proven muscular atrophy type I? Paediatric Respiratory Reviews 2008; 9:55-56.

35. Bach JR. The use of mechanical ventilation is appropriate in children with genetically proven muscular atrophy type I: the motion for. Paediatric Respiratory Reviews 2008; 9:45$\underline{50 .}$

36. Ryan MM.. The use of invasive ventilation is appropriate in children with genetically proven muscular atrophy type I: the motion against. Paediatric Respiratory Reviews 2008; 9:51-54.

37. Simonds AK Respiratory support for the severely handicapped child with neuromuscular disease: ethics and practicality. Semin Respir Crit Care Med 2007; 28:342-54. 
38. Profit J, McCormick MC, Escobar GJ, Richardson DK, Zheng Z, Coleman-Phox K, Roberts R, Zupancic JAF. Neonatal Intensive Care Unit Census Influences Discharge of Moderately Preterm Infants. Pediatrics. 2007; 119:314-319.

39. Sherman JM, Davis S, Albamonte-Petrick S, Chatburn RL, Fitton C, Green C et al. Care of the child with chronic tracheostomy. Am J Respir Crit Care Med. 2000;161(1):297-308.

40. Jardine E, Wallis C. Core guidelines for the discharge home of the child on long-term assisted ventilation in the United Kingdom. UK Working Party on Paediatric Long Term Ventilation. Thorax. 1998;53(9):762-7.

41. Perrin J, Erenberg G, LaCamera Rea. Guidelines for home care of infants, children, and adolescents with chronic disease. American Academy of Pediatrics Committee on Children with Disabilities. Pediatrics. 1995;96(1Pt1):161-4.

42. Wang KW, Barnard A. Caregivers' experiences at home with a ventilator-dependent child. Qual Health Res. 2008;18(4):501-508. 
1

2

3

4

5

6

7

8

9

10

11

12

13

14

TABLE 1 Children's characteristics and type of ventilation

\begin{tabular}{|c|c|c|c|}
\hline Characteristics & $\begin{array}{c}\text { Invasive } \\
\text { ventilation }\end{array}$ & $\begin{array}{l}\text { Noninvasive } \\
\text { ventilation }\end{array}$ & Total \\
\hline No. of subjects & 149 & 213 & 362 \\
\hline Male/female, $n$ & $87 / 62$ & $116 / 97$ & $203 / 159^{\mathrm{al}}$ \\
\hline \multicolumn{4}{|l|}{ Area of residence ${ }^{b}$} \\
\hline Northern Italy & 84 & 115 & 199 \\
\hline Central Italy & 21 & 35 & 56 \\
\hline Southern Italy & 44 & 63 & 107 \\
\hline Age, median (interquartile range), $y$ & $6(3-9)$ & $11(5-15)$ & $8(4-14)^{\mathrm{cl}}$ \\
\hline \multicolumn{4}{|l|}{ Age at start of mechanical ventilation } \\
\hline median (interquartile rage), $y$ & $1(0-4)$ & $8(3-13)$ & $4(1-11)^{\mathrm{c} 2}$ \\
\hline \multicolumn{4}{|l|}{ Time on ventilation support } \\
\hline median (interquartile range), $y$ & $3(1-5)$ & $1(0-2)$ & $1(0-4)^{c 3}$ \\
\hline \multicolumn{4}{|l|}{ Major diagnostic category $^{\mathrm{d}}, n$} \\
\hline Neuromuscular disorders & 66 & 112 & 178 \\
\hline Chronic lung and upper respiratory diseases & 12 & 52 & 64 \\
\hline Hypoxic (ischemic) encephalopathy & 31 & 17 & 48 \\
\hline Abnormal ventilation control & 25 & 19 & 44 \\
\hline Spinal cord injury & 10 & 1 & 11 \\
\hline Chest anomalies & 4 & 12 & 16 \\
\hline Other & 1 & 0 & 1 \\
\hline \multicolumn{4}{|l|}{ Hours/day spent under mechanical ventilation } \\
\hline$<12 / \geq 12, n$ & $29 / 120$ & $178 / 35$ & $207 / 155^{\mathrm{a} 2}$ \\
\hline \multicolumn{4}{|l|}{ entilation monitoring modality, $n$} \\
\hline$\underline{\text { Pulse oximetry (saturation) }}$ & $\underline{136}$ & $\underline{144}$ & $\underline{280}$ \\
\hline Cardiovascular/respiratory leads & $\underline{8}$ & $\underline{29}$ & $\underline{37}$ \\
\hline
\end{tabular}

Formatted: Font: Not Bold

Formatted: Font: Italic

Formatted: Indent: Left: $12.6 \mathrm{pt}$, Tabs: 12.6 pt, Left

Formatted Table

Formatted: Indent: Left: $12.6 \mathrm{pt}$, Tabs: $12.6 \mathrm{pt}$, Left 
1

2

3

4
Formatted: Indent: Left: $12.6 \mathrm{pt}$, Tabs: $12.6 \mathrm{pt}$, Left

Formatted: Indent: Left: $12.6 \mathrm{pt}$ Tabs: $12.6 \mathrm{pt}$, Left

Formatted: Indent: Left: $12.6 \mathrm{pt}$
${ }^{\mathrm{a} 1}: \chi^{2}=0.55 ; \mathrm{P}>0.459 ;{ }^{\mathrm{a} 2}: \chi^{2}=148 ; \mathrm{P}<<0.001 ;{ }^{\mathrm{a} 3}: \chi^{2}=115 ; \mathrm{P}<<0.001$

b: $\chi_{\text {trend }}^{2}=0.07 ; \mathrm{P}>0.80$

${ }^{\mathrm{c}}$ Mann-Whitney U test: ${ }^{\mathrm{c} 1}=-6.147 ; \mathrm{P}<<0.001 ;{ }^{\mathrm{c} 2}:=-8.733 ; \mathrm{P}<<0.001 ;{ }^{\mathrm{c} 3}=5.873 ; \mathrm{P}<<0.001$

d: $F=5.94 ; P<0.016$ 
Deleted: TABLE 2 Ventilation monitoring modality according to the type of ventilation used 9

Modality 


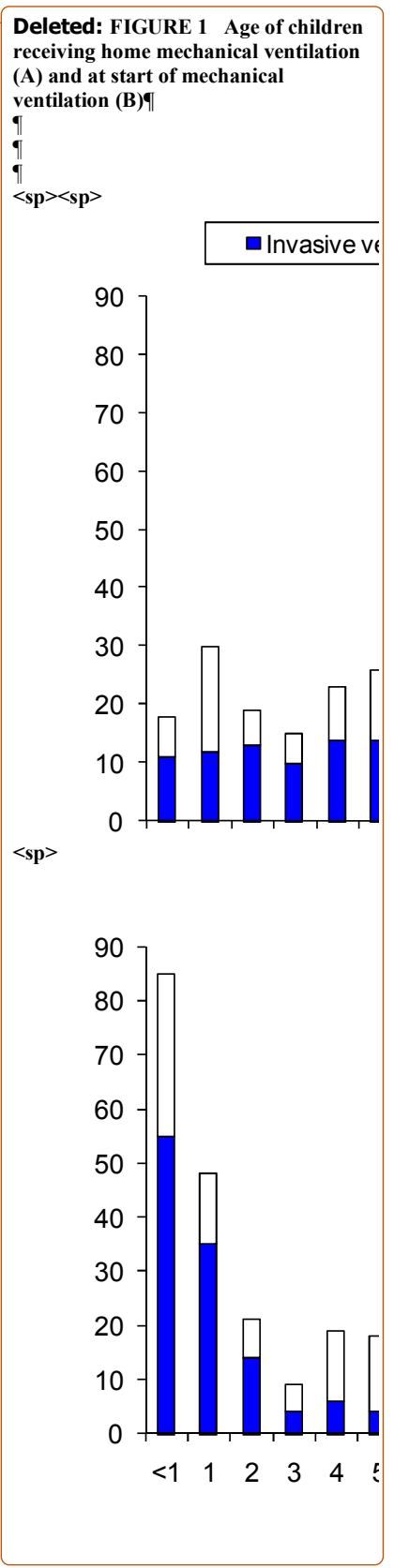


TABLE 2 Ventilation monitoring modality according to the type of ventilation used

\begin{tabular}{|l|c|c|c|}
\hline \multicolumn{1}{|c|}{ Modality } & $\begin{array}{c}\text { Invasive } \\
\text { ventilation } \\
\boldsymbol{n}(\mathbf{\%})\end{array}$ & $\begin{array}{c}\text { Noninvasive } \\
\text { ventilation } \\
\boldsymbol{n}(\boldsymbol{\%})\end{array}$ & $\boldsymbol{n} \mathbf{( \% )}$ \\
\hline Pulse oximetry (saturation) & $136(84)$ & $144(67)$ & $280(74)$ \\
\hline Cardiovascular/respiratory leads & $8(5)$ & $29(14)$ & $37(10)$ \\
\hline End tidal $\mathrm{CO}_{2}$ & $11(7)$ & 0 & $11(3)$ \\
\hline None & $3(2)$ & $38(18)$ & $41(11)$ \\
\hline Other & $4(2)$ & $3(1)$ & $7(2)$ \\
\hline
\end{tabular}

The figures do not add up to $100 \%$ because some patients used more than one monitoring modality. 